\title{
A Conceptual model for barrier free facilities planning
}

\author{
R. S. Bittencourt ${ }^{\mathrm{a}^{*}}$ and L. B. de M. Guimarães ${ }^{\mathrm{a}}$ \\ ${ }^{a}$ Federal University of Rio Grande do Sul, Av. Osvaldo Aranha 995 o andar, Porto Alegre, Brazil
}

\begin{abstract}
This paper presents the proposal of a model for planning a barrier free industrial facilities, considering the demands that inclusion requires, ranging from outside the factory (social environment), to the needs of the production system and the workstation. Along with literature review, the demands were identified in a shoe manufacturer that employs people with disabilities, and organized taxonomically in agreement with the structure for planning facilities. The results show that the problems are not primarily related to eliminating architectural barriers and factors aimed at preventing risks to people's health and safety but, rather, are related to the company's cultural environment, because the main hazards are managerial. In special cases, it is suggested there is a need to adjust those parts of tasks that the worker cannot do, or even to re-schedule work so as to make it possible for employees with disabilities to perform their tasks.
\end{abstract}

Keywords: social responsibility, accessibility, people with disabilities, planning, industrial facilities

\section{Introduction}

Project planning is a complex task which demands multi-disciplinary team work considering that the involved variables are dependent on knowledge from different disciplines, such as the social sciences, engineering, design, administration etc. However, in most projects, it is not common to find these kinds of teams at the conception, development or finalization stages, no matter whether the project is for a simple consumer product or a complex plant. Some research carried out in the state of Rio Grande do Sul, Brazil, with designers, engineers and architects $[11,13]$ made it clear that, in general, project professionals do not work in multidisciplinary teams, do not have a formal method for architectural design, but usually start generating ideas by developing a needs plan (briefing) with the owners and/or managers. They often have a preconceived notion of what they intend to build, based on their previous experience and what famous designers around the world are doing. In the case of designing an industrial plant, it is very common, in Brazil, to project by square meters i.e. to plan according to the shape and size of the terrain, using pre- fabricated materials with no attention being paid to the kind of work that will be carried out in the factory. This explains why so many factories in Brazil offer no comfort whatsoever to those who work in them, such that they feel uncomfortably hot in the summer, and unreasonably cold in the winter. In addition to these forms of thermal stress, they suffer, the whole year through, from the emotional one that arises from feeling encaged because of the lack of windows, a sort of stress that could be minimized if they, at least, had a view to the outside. The concept of the plant factory as a cage is rooted in the old idea that people will be distracted by stimuli from the outside. In fact, completely the opposite is true, since the absence of stimuli leads to monotony (and a drop in the attention span) while the availability of stimuli (like the external variations in light, the movement of trees etc) tends to keep people more alert and, therefore more attentive while performing their work [16].

The same lack of attention to people and their jobs can be found when the layout of a plant is being planned. Industrial engineers are generally trained to focus on the process itself but not on the people working on it. As a result, when the plant starts to operate, many ergonomic problems emerge. While many can be adjusted, others are beyond solution which results in high

\footnotetext{
* Corresponding author. Email: rosisb@ig.com.br
} tel: $+55513308-3948$ fax: $+55513308-4007$ 
costs both for the people involved and production. One way to build better plants for people to work in is to use ergonomics in the conceptual phase prior to construction and in the construction process itself. However, it is exceptionally rare to find projects like this. Among the few examples have been the Volvo plants in Kalmar and Udevalla which were planned according to the workers' needs and wants [4], the sanatorium in Paimio, Finland, designed in 1929 by architect Alvar Aalto [8] and the Sarah hospitals conceived by architect João Figueiras Lima (Lelé) [17] in Brazil, who understand that the successful convalescence of patients depends on contact with nature, and good natural illumination and ventilation.

Another important point is the fact that designers do not often consider the full range of abilities or disabilities among the potential working population. There is no such thing as a "normal" person, and to attempt to design for one is to design for almost nobody. All individuals, at some point in their lives, have some kind of abnormality, temporarily or permanently: the very tall or very small person, pregnant women, those carrying bags, luggage, materials or pushing a baby stroller, or even just the fact of there being children or elderly; people who break an arm or sprain an ankle, and so on. Everybody has already needed, currently needs or will need means for mobility and/or communication [9, 3].

Fostering accessibility has been sought by many means including that of eliminating barriers to access $[1,2]$. The inclusion of people with disabilities or with reduced mobility into society has been focused on projects: for residential facilities [21,22,23], in the public municipal environment $[24,25,26]$, including in educational environments $[27,28,29,30]$, hospitals [31] and means of transportation [32]; and technical and organizational re-design of worksites, based on risk assessment [12]. In such projects, different techniques and guidelines have been developed and applied, such as: the US Federal Law Americans with Disabilities Act ADA [1] which, within the framework of measures preventing discrimination against people with disabilities, coined the term "reasonable accommodation", "reasonable" standing for "not putting an undue burden on the employer" while the term "accommodation" referring to arrangements such as overall accessibility of the working environment, technical redesign of the worksite, assistive devices to help perform working tasks, reorganization of work processes and/or workflow and personal assistance when needed; the seven principles of Universal Design (UD) [15] which mainly focus product design: equitable use, flexibility in use, simple and intuitive use, perceptible information, tolerance for error, low physical effort, size and space for approach and use; and the Universal Design New York [14], which adapted the seven principles of UD to buildings and introduced the elements of the Universal City, where 12 guidelines for workplace facilities are included (general environment, lighting, thermal environment, noise, layout of work areas, materials flow, handling and storage, social interaction, workstations, standing workstations, sitting workstations, sit-stand workstations and computerized workstations).

Despite the call for "reasonable accommodation" [1] and the need to design layouts of work areas considering social communication and social interaction [43], practical applications of the Universal Design in the industrial sector have been limited to product design [20] looking for micro-oriented solutions by focusing on a group of requirements related to the physical aspect of accessibility, and are not specifically linked up to the scope of planning the work organization. However, the global movement towards inclusion points to the need to rethink how each professional can contribute in his/her area of performance in the quest for a better, more caring society [33]. Using this outlook, with regard to the scope of planning industrial facilities, the industrial engineer can also make a contribution [6] designing industrial facilities that are planned so as to be free of barriers that impede or hinder the safe access and circulation of people, including people with disabilities or with reduced mobility [5]. Considering this is still an incipient area of research, although engineers may seek complementary information in order to make industrial facilities as free from barriers as possible, it is highly unlikely they would be successful in this task. This is due to the fact that this information is scattered piecemeal both throughout the literature (legislation and normative instructions related to inclusion, inclusion models and project techniques) and in the practical experiences of individuals in different areas of knowledge, of different entities and of people with disabilities themselves [6].

References on the compulsory nature of adhering to ADA were identified in the work of [10] who offers recommendations about how to comply with the need to follow the Act, and [17] who, besides recommending the use of this Act, raise other considerations on this subject in their item denominated "barrier-free compliance", where they approach the theme by pointing out the anthropometric differences among people who use a wheel chair for locomotion and those who do not. According to these authors, such differences should be reflected at the workstation, in tables and reach areas. In fact, their study does not go on to list other demands to be addressed and does not offer guidelines on tasks to be undertaken so that the project resulting from planning can be considered free from barriers, in order to make access possible for the maximum possible number of people, and so as to include people with disabilities or those with reduced mobility. 
According to Brazilian legislation $\mathrm{n}^{\circ} 10.098,2000$ [7], a barrier to access is "any impediment or obstacle that limits or impede the access, freedom of movement and safe circulation of people", both with regard to barriers of the passages or spaces of public use (town architecture) as well as inside public and private buildings (architectural construction), in the means of transport (architecture in transport) or in the means for expressing and receiving messages (communication barriers). Eliminating such barriers enlarges the scope of inclusion, and seeks not only to benefit those with severe disabilities but also anybody with reduced mobility, whether temporary or definitive. Again, these set of barriers do not include the ones related to work organization, i.e., the ones which impede people to perform their tasks.

The lack of literature on inclusion of people with disabilities on production processes opens up a research field that could change the way plants and its work organization are designed. The study presented in the following sections aims to start filling this gap by contributing to the development of more inclusive industrial facilities projects, i.e., a barrier free project.

\section{Method}

The denominated "Barrier Free Industrial Facilities Planning" model was developed based on the necessary demands of inclusion, through the incorporation of related information from outside the factory (social environment), from the production system to the workstation. The study was conducted in three stages: I) eliciting the demands for inclusion;

II) identifying/validating demands based on a real context of inclusion; III) developing a conceptual model for the planning of barrier free industrial facilities based on the information obtained in the previous stages of the research.

I) Stage I: the objective was to identify the largest number of possible demands for the inclusion of people with disabilities or people with mobility impairments in the job market, in order to develop a list of such demands arising from different sources of information gathered in an integrated way and convergent to the focus of interest of this research. The demands were identified by: a) literature knowledge based on bibliographical research upon legislation, effective normative instructions, inclusion models and project techniques; b) tacit knowledge based on a participative research with professionals of different areas of performance, including representatives of assistance entities and people with disabilities.

a) the sources of information used on the bibliographical research were: [34,35,36,37,1,2,7]. A complete (population=sample) and systematic reading was made of a total of 143 documents; the scope of this research took in Brazilian Federal legislation and mentioned North American Legislation; ii) inclusion models and national and international project techniques: this information was gathered from representative models of national and international institutions that act on behalf of inclusion, through asystematic research including: the International Labor Organization, the World Health Organization, Coordenadoria Nacional para Integração da Pessoa Portadora de Deficiência, Associação de Pais e Amigos dos Excepcionais (APAE), ETHOS Institute, etc.; iii) scientific journals, national and international theses and dissertations by means of thorough systematic research in databanks made available by CAPES Portal to Periodicals which offers access to the complete texts of articles of more than 12,365 national and international magazines, and 126 data bases [38]. Each publication related to the theme was analyzed for its applicability and contribution to this study.

b) the tacit knowledge was obtained by a survey with 136 professionals from six different knowledge areas (12 physicians, 60 physiotherapists, 18 occupational therapists, 19 industrial engineers, 20 administrators and 7 ergonomists), 11 representatives from care institutions and 22 people with disabilities, conducted to find out their perceptions regarding the demands for the inclusion of people with disabilities in the job market and, specifically, in the industrial sector.

II) Stage II: the purpose of the case study was the identification/validation of the demands for inclusion based on a real context, in a participative way, with individuals who had contact with successful cases of inclusion of people with disabilities on the shop floor. Empirical knowledge derived from a field study carried out over 9 months (from August 2005 to May 2006) in a shoe manufacturer plant (classified as a 3rd degree risk), located in the state of Rio Grande do Sul, Brazil, which in 2005-2006, employed directly 6 people with disabilities in the production process ( 1 with physical disability, 1 with hearing impairment and 4 with mental impairment). In 2008 , the number increased to 15 people (2 with physical disability, 1 with hearing impairment and 12 with mental impairment).

The experience undergone by the Company is a differential for this research, not least because the demands related to the inclusion of people with disabilities is barely adressed by national and international legislation. All the participants signed a term of free and informed consent, as prescribed by Resolution 196/1996 of the National Council of Health of the Ministry of Health published in the Diário Oficial number 201, 16/96. It is worth noting that because the employees with disabilities could not sign a consent form for participating in the study, APAE, the institution in charge of the inclusion 
process, assumed the responsibility for their participation.

In total, there were 559 individuals involved, directly or indirectly in the field study. Collecting data to identify the demands for inclusion was accomplished in agreement with the first three stages of the participative Macroergonomic Design (MD) tool [39, 40]: i) identifying the user and the organized collection of information, ii) Prioritizing the Items of Ergonomic Demand (EDIs) identified by the participants and; iii) Incorporating specialists' opinion. Open interviews were used, which were recorded and in agreement with the order and frequency of the items mentioned, a weight related to the importance of the item was given in order to compile the questionnaires. The questions in the questionnaires made it possible to measure, quantitatively, the degree of importance/concordance of each EDI. Measurements were taken from the score that each respondent gave on a continuous scale of $15 \mathrm{~cm}$, as suggested by [41], with two anchors in the extremities (totally disagree or 0 and totally agree or 15). The questionnaires showed good internal consistency (alpha $=0.71$ ) according to Cronbach's Alpha [14], data were tabulated and prioritized, and the weight of the EDI was generated by its arithmetic mean for later use in descriptive statistics and nonparametric statistical tests, because data did not display normal distribution. This article discusses only the results from those who work directly with the people with disabilities: 34 employees from the company (8 working with people with physical disabilities, 15 working with the person with hearing impairment and 11 working with people with mental impairment) and 7 APAE employees. The results from the Company group were analysed with the Kruskal-Wallis test in order to compare the responses as a function of the type of respondent (i.e., co-working with people with physical, hearing or mental impairment). The results with a statistical difference ( $p$-value $<0.05$ ) were analysed with the nonparametric Tukey test to complement the averages comparison. The responses of the APAE group and the Company one were compared with the non-parametric Mann Whitney U test.

III) Stage III: the information collected by means of the case study was used in Stage III to develop the proposed model, thus making it feasible to add to the model considerations about practical experiences experienced by the company studied.

\section{Results}

\subsection{Results from the literature reviewed}

From Capes Portal it was found only 6 articles in journals related to people with disabilities in 19861990,6 articles in journals +6 thesis and/or dissertations in 1991-1995, 6 articles in journals +52 thesis and/or dissertations in 2000-2005. It is clear that the subject got more importance in the last period. In general, the literature reviewed focus on the physical aspects of the accessibility, with exceptions related to the people with visual and hearing impairment.

\subsection{Results from the tacit knowledge research}

All professionals from the six areas of knowledge, the representatives from the care institutions as well as the people with disabilities consider important and relevant the inclusion of people with disabilities in the work environment. However, they do not feel the professionals are qualified for developing an inclusion process and understand that inclusion in Brazil will be slow and difficult to implement. The reason is the lack of training of the professionals, and the fact that the companies and society as a whole are not prepared to deal with people with disabilities.

\subsection{Results from the case study}

In relation to achieve the inclusion of people with disabilities in the workplace, the non-parametric Mann Whitney $U$ test showed that the answers from the Company's employees and APAE differ on the necessity to have good knowledge of the impairments of these people in order to include them better in the work environment $(p=0.41)$; on the necessity for there to be suitable professional monitoring during the process of including people with disabilities in the company ( $p=0.49$ ) to conduct appropriate professional monitoring to check if the inclusion is working out correctly $(p=0.009)$; on the necessity to have good knowledge of the job to be performed in order to include them in the company ( $p=0.009)$; on the necessity to have good knowledge of the skills of the people with disabilities in order to include them better in the work environment $(\mathrm{p}=0.009)$; and on the necessity that the work team is trained to receive people with disabilities $(p=0.001)$. The APAE group value those items more than the company group.

The perception of the company staff is that the boss knows how to manage the person with disability (and has also been prepared to work with such people. However, the Mann Whitney $U$ test showed that the Company group and the APAE one do not agree, to the same 
extent, that superiors (bosses, foremen, etc.) are prepared to work with other people with disabilities $(\mathrm{p}=0.05)$. The employees feel they were sufficiently prepared to work with a member of the staff with disabilities. The Kruskal-Wallis test showed that the perception of the staff working with people with mental impairment is that the possibility of training them is low differing $(\mathrm{p}=0.009)$ from the opinion of the staff working with people with physical or hearing impairment. All respondents agree (there was no significant statistical difference among the answers) that the boss makes the same demands of the staff with disabilities as of other staff but, on the other hand, the staff with disabilities has privileges that all other staff should have such as: trips to the bathroom and to drink water. The Kruskal-Wallis test showed a difference $(\mathrm{p}=0.025)$ between the opinions of the team working with the hearing impaired person and the teams working with mental and physical impaired people about the question "the boss never asks the people with disabilities to do unnecessary jobs". The former understands that this is not true for the hearing impaired person.

All the interviewees agree that they like working with people with disabilities, and that they get on well with co-workers and with the boss. Besides, for the staff, the entry of the people with disabilities in the team has made the boss's relationship with his work team better and that with the entry of the people with disabilities, the work environment got better. However, the Mann Whitney $U$ test showed that the Company group and the APAE one do not agree, to the same extent, that the work team likes working with the person with disabilities $(p=0.021)$.

Although it could not be statistically proved, due to the lack of productivity data, the company group and APAE perceive an improvement in the productivity of the team with the inclusion of such people: production was not adversely affected and the member of the staff with disabilities does his/her job correctly. However, the company team that works with people with physical impairment understands that their inclusion had a negative impact on production (Kruskall-Wallis test, $\mathrm{p}=0.023$ ). As assessed by the employees, the inclusion of people with disabilities was successful.

With regard to the company's access infrastructure for inclusion, the company's employees consider the workstations and the building are appropriate while the APAE team is not as satisfied $(p<0.001)$. According to the Company's directors, when the current building was designed, the middle managers stated "that it had to be accessible, so that the company could re- ceive visitors with disabilities". The accessibility conditions of the municipality were considered inadequate.

The experience undergone in this company is a differential for this research study, for the additional reason that the demands related to the inclusion of people with mental disabilities are to a very large extent not addressed either by NBR 9050 or other pertinent national legislation. Moreover, with these results, it could be seen that there is a tendency for professionals working in the care organization (APAE) to demonstrate more dissatisfaction with the demands of accessibility than the company's employees. This may be due to objectives of the APAE professionals, whose daily routine is to be involved in the inclusion process, therefore tending to seek continuous improvement of environments in favor of people with disabilities.

Among the differentials identified by means of this study, what stands out is that the success of the inclusion of people with disabilities with characteristics is related to the production subsystem and the personnel subsystem, such as the work organization (i.e., flexibility was a base element on several occasions). The rhythm of production is not dictated by a conveyor belt what made it sufficiently viable to allow the inclusion of people with disabilities, gradually, and to respect their individual differences. Moreover, the procedure used by each person with disabilities to develop his/her task followed his/her individual preferences. Flexibility should also be extended to work quality requirements, attendance, and work and breaks schedule.

Among the issues already addressed by the literature, this case study may well reinforce the importance of meeting demands such as: a flexible work organization to support the different capabilities for each task to be performed by the people with disabilities, there being a team of specialists to implement and/or support the process of inclusion, and the effective commitment of senior management to inclusion.

\subsection{Compiled results from stages I and II}

The total group of demands identified by means of Stages I and II includes the demands based on the literature and tacit knowledge, and the demands arising from the case study, which ranged from subjects related to the external environment of the industrial facilities, such as the local accessibility, including the means of transportation and accessible routes, to demands related to the production system and the work organization.

The results show that, although the literature focus on physical solutions, the problems are not primarily related to the elimination of architectural barriers and prevention of health and safety risk factors 
but, rather, related to the company's cultural environment, because the main hazards are managerial. Therefore, the installation of a real free barrier environment asks for the trainning and involvement of effective management and employee commitment with the inclusion process, and allocating people in jobs they are capable to carry on. In special cases, it is suggested that there is a need to adjust parts of the tasks that the worker cannot accomplish, or even conforming work schedules to make possible the accomplishment of such tasks by employees with disabilities.

\subsection{Modelling the barrier free facilities planning}

Stage III sets out the detail of the draft conceptual model. The objective is to use language that is close to that of an engineer's work routine. The proposed model aimed to be structured using a model for the planning of industrial facilities, which has received recognition and acceptance from the academic community. However, it was identified that there is no consensus in the literature about the theme. Thus, the model was chosen after evaluating the bibliographical references recommended for the disciplines of "Factory Project", or similar disciplines, which are taught on courses of industrial engineering at Brazilian federal universities. The selection was made, in the first instance, based on the number of universities that recommended the same model. The works of [10] and [18] were found to be in equal first place, each having been recommended by $8 \%$ of the universities. The tie-breaker criterion used was to choose the model that was the more didactic as to its use. Based on the selection criteria, the work selected was "Facilities and Workplace Design" [10].

Having defined the structure, the demands were analyzed individually as to their applicability throughout the stages of planning the facilities and the case study made the validation of these possible, in accordance with the scope of the study. Thereafter, the demands were organized synthetically and taxonomically as do-able activities and actions throughout planning, and sought to ensure the final result is free from barriers.

In the framework for planning of facilities [10], designing of the facilities is subdivided in five levels in accordance with the level of inclusion of the activities in relation to the environment. Each one of these levels includes a group of activities to be performed during the drafting of the design plan. This form of organization served as a structural base for Stage III: the framing of the demands for inclusion in the Barrier-free Industrial Facilities model proposed.

Basically, the levels of the model should fully provide for the following main activities: i) determining the mission and location of the company by taking into consideration the advantages and disadvantages of each site from the point of view of its accessibility; ii) drafting the planning of the site, so that the ground plan is accessible for current and future use; iii) defining the layout of the facilities, and pointing out the advantages and disadvantages of each proposal from the point of view of accessibility; iv) projecting the layout of the departments considering the accessibility needed to meet the demands for personal space and communication and; v) projecting the work stations so that they optimize productivity, are integrated and enhance the work experience of those involved.

During the unfolding of each level of planning, the demands to be met are presented with regard to national legislation, the principles of Universal Design and other complementary information. This is where the considerations related to the contribution of the case study to the model are included.

In Level I, the information should be collected through check-lists in order to create a ranking of accessibility for the candidate sites, based on scores that reflect the importance of each factor to satisfy the strategy of accessibility defined for the new facilities. In this Level the specific tasks are: i) Obtaining information on accessibility and social inclusion; ii) Developing strategy related to accessibility and social inclusion; iii) Identifying accessibility for the selected land (sites); iv) Evaluating candidates pointing out advantages and disadvantages of each site from the point of view of accessibility.

With regard to Level II, its main contributions to accessibility are: its use of the information collected so far so as to permit a critical analysis of the layouts developed for the site selected; being able to point out the advantages and disadvantages for each of the propositions in relation to the necessary items of demand so as to assist the strategy defined for accessibility, in the previous level of the project. The group of specific tasks requirements that comprise the planning of industrial barrier-free facilities for Level II is: i) Improving/Confirming the relevant information so as to guarantee accessibility; ii) Layout with occupation of the land and of the alternative places which assist the accessibility demands; iii) Evaluating the layout and pointing out advantages and disadvantages of each of the layouts from the point of view of accessibility.

Level III considers the planning of the industrial facilities interior, including the analysis of the obligatory accessible routes inside the facilities and, in a comple- 
mentary way, the accessible routes already defined in the previous level. It is suggested that these routes be analyzed as units of space planning. Thus, the developed layouts can be adapted for the relative minimum demands to the escape routes and the main access to the factory ground, etc. The specific tasks for this level are: i) Identifying the accessibility demands in relation to the existing physical structure; ii) Identifying the accessibility demands in terms of obligatory accessible routes (emergency exits, main entrance, access to the factory grounds, etc.) or desirable (alternative or complementary routes); iii) Calculating space considering the accessibility parameters; iv) Identifying limitations as to the accessibility demands; v) Generating options of space planning taking into consideration accessibility demands (obligatory routes, desirable routes, etc.); vi) Analyzing the options of space planning pointing out the advantages and disadvantages of each layout from the point of view of accessibility.

The demands identified in the previous level should be detailed in Level IV, in order to develop the layouts of the departments after taking into account the accessibility demands. This level suggests the design of environments that promote efficient materials flow, minimize manual materials handling and facilitate social communication and social interaction [42], and the structured recruitment, selection, hiring and development (permanence and promotion) program for all people. To make the inclusion of people with different cognitive impairments viable, or even to accommodate different needs and/or unexpected contretemps of the employees, there is a proposal for this being seen to conform with elements of the production system as a basic requirement for the success of the inclusion, among which the rhythm of production mentioned. A flexible rhythm can make the gradual transfer of new work to the employee possible, while respecting different variations in the form of and time necessary for learning; which would not be possible with a fixed rhythm of production determined by a conveyor belt production line. Also, a flexible schedule of attendance, work and breaks, as well as flexibility in relation to the quality of work are fundamental for inclusion. In this Level, the specific tasks are: i) Selecting products and processes taking into account both physical and cognitive accessibility demands; ii) Projecting layouts of cells/lines taking into account both physical and cognitive accessibility demands; iii) Evaluating the layout options which include pointing out their advantages and disadvantages from the point of view of accessibility.
Level $\mathrm{V}$, the last of the planning phase, seeks to conceive an accessible, productive, comfortable and safe work environment, taking into account the legislation of effective accessibility. It endeavors to find ways to maximize results without making accessibility unfeasible and to generate the greatest possible access to workstations, without compromising the effectiveness of the work environment. The specific tasks for this Level are: i) Identifying the applicable accessibility demands at this level; ii) Conceiving the layout options taking into account, for all the items, both physical and cognitive accessibility demands; iii) Identifying the limitations from the point of view of accessibility; iv) Generating options of space planning taking into account both physical and cognitive accessibility demands; v) Evaluating the options of space planning while pointing out the advantages of each project from the point of view of accessibility.

\section{Conclusions}

This article presented a "Conceptual Model for Planning Barrier-free Industrial Facilities" developed to be used as guide for the planning of industrial facilities to make the project accessible from its conception phase, which is generally easier and cheaper than making later corrections, when the project is in its late phase of implementation. It contains a structured group of recommendations developed based on the demands for inclusion of people with disabilities in industrial facilities, as depicted from the literature review, the experts's opinion and the experience from a real context of inclusion: a successful case study of inclusion of people with disabilities in an footwear manufacturer plant.

The model's approach is much more than that of eliminating architectural barriers and preventing factors related to putting health and safety at work at risk. The intention was to address issues on the relevance of considering the full range of diverse needs of human beings in the design solutions and to integrate the essential requirements for accessibility, by incorporating variables related as much to the external as the internal environment of the facilities. It stresses the need for the consideration of both physical and cognitive demands, the involvement and effective commitment of senior management, as well as the involvement of employees. It emphasizes that work organization, mainly the work content, the type of tasks and work schedules should be adjusted to the worker capability, needs, and wishes so as to make it possi- 
ble for all employees, including the ones with disabilities, to accomplish their tasks.

The proposed model [19] sets out to discuss the integrative solutions that can be used in educating and training future production engineers in order to facilitate their performance in the conception of barrier-free industrial facilities, and thus making the environment of industrial work accessible to people with disabilities or those with reduced mobility. This will contribute towards meeting the burgeoning and necessary demand for those individuals' inclusion and, as a consequence, supporting one of the social responsibility objectives of the new facilities. The goal is accommodating all individuals, including those with disabilities, so that all adults have the opportunity to participate in work successfully.

\section{References}

[1] Americans with Disabilities ACT - ADA, The Americans with disabilities Act. Available at: <http://www.eeoc.gov/ada/> 1990,Accessed on: 10/07/2011.

[2] Americans with Disabilities Act And Architectural Barriers ADAAG, Act accessibility guidelines: United States access board a federal agency committed to accessible design. Washington, D.C. 2002, Available at: < http://www.access-board.gov/adaag/about/>, Accessed on: 23/07/2011.

[3] M.L. Amiralian et. al., Conceituando deficiência. Revista Saúde Pública, São Paulo 34 (1), 2000, 97-103.

[4] C. Berggren, Alternatives to Lean Production: Work Organization in the Swedish Auto Industry. Ithaca, NY: ILR Press, 1992.

[5] R.S. Bitencourt et al., Fábrica da inclusão: a Viabilidade de Concepção de um Sistema Produtivo Inclusivo. Proceedings of the Congresso Brasileiro de Ergonomia. Associação Brasileira de Ergonomia, Fortaleza, 2004.

[6] R.S. Bitencourt et al., Perspectivas Multidisciplinares sobre a Inclusão de PPDs no Mercado de Trabalho: Buscando a Inclusão Produtiva no Setor Industrial. Proceedings of the Encontro Nacional de Engenharia de Produção. Associação Brasileira de Engenhraia de Produção, Porto Alegre, 2005.

[7] Brazilian Legislation, Legislação Brasileira sobre Pessoas Portadoras de Deficiência. Coletânea - Brasília: Câmara dos Deputados. Coordenação de publicações, 2000.

[8] Danisch Architeture Center, Available at: http://sustainablecities.dk/en/experts, Accessed on: 17/06/2011.

[9] Ethos, O compromisso das empresas com as metas do milênio. São Paulo: Empresa e Responsabilidade Social. 2004.

[10] Q. Lee, Projeto de Instalações e do Local de Trabalho. 1. ed. IMAM, São Paulo, 1998.

[11].S. Pons, Projeto de Arquitetura de Interior para uma Sala de Controle: um Estudo de Caso com um Método Ergonômico Participativo. Dissertation (MEng.). Universidade Federal do Rio Grande do Sul, 2004.

[12] L. Pigini, et al., Designing reasonable accommodation of the workplace: a new methodology based on risk assessment. Disability and Rehabilitation: Assistive Technology, May 2010.

[13] A.Tramontin, Identificação dos Itens de Demanda Ergonômica em Lojas de Cosméticos e Perfumes. Dissertation (MEng.). Universidade Federal do Rio Grande do Sul, 2000.

[14] L. J. Cronbach, Coefficient alpha and the internal structure of tests. Revista Psychometrika, ed. 16, pp. $297-334$.
[15] University of North Carolina, 1997. The Center for Universal Design. Available at: http://www.design.ncsu.edu/cud/ about ud/udprinciplestext.htm Accessed on: 22/07/2011.

[16] A. Kroemer and E. Grandjean, Manual de Ergonomia Adaptando o trabalho ao homem. Porto Alegre: Bookman, 2005.

[17] L. Toledo, Feitos para Curar - arquitetura hospitalar e processo projetual no Brasil. Rio de Janeiro: ABDEH, v.1, 2006.

[18] J. Tompkins, et al., Facilities Planning. New York: John Wiley \& Sons. 1996.

[19] R. S. Bitencourt, Proposta de um Modelo Conceitual para o Planejamento de Instalações Industriais Livre de Barreiras. Thesis. Universidade Federal do Rio Grande do Sul, 2008.

[20] EQUAL. Extending quality life: Annual Report. Accessed on: 28/11/2003, Available at: www.fp.rdg.ac.uk/ equal/

[21] A. Frattari,et al., Smart home and architecture: The case study of dwellings for people with cognitive disabilities. International Journal for Housing Science and Its Applications, 31(2), 89-98. Retrieved October 15, 2007, from Scopus database.

[22] B. Niva and L.Skär, A pilot study of the activity patterns of five elderly persons after a housing adaptation. Occupational therapy international, 13(1), 21-34. 2006. Retrieved October 15, 2007, from Scopus database.

[23] C. P. Johnson, T. Kastner, Helping families raise children with special health care needs at home. Pediatrics, 115(2), 507-511. 2005. Retrieved October 15, 2007.

[24] M, Araújo et al., Estudo da Acessibilidade Empregando Modelagem de Dados Espaciais - MDE - estudo de caso: rampas. Programa de Pós-Graduação em Ciências Geodésicas e Tecnologias da Geoinformação Universidade Federal de Pernambuco - UFPE. Pernambuco. 2007.

[25] V. Bins Ely et al., Projeto de Espaçoes Livres Públicos de Lazer para Todos. Grupo PET Arquitetura e Urbanismo. Universidade Federal de Santa Catarina. Santa Catarina. 2006.

[26] H. Miyazawa, The urban built environment and inaccessibility: A case study of the early developed area of Tama New Town, Tokyo, 2004.

[27] NJSCC - New Jersey schools construction corporation. 21st Century Schools: Design Manual. New Jersey. May 15, 2007.

[28] S. Gilman, Including the child with special needs: Learning from Reggio Emilia Theory into Practice, 46(1), 23-31. Retrieved October 15, 2007, from Scopus database.

[29] J. Stewat-Pollack, L.E.Pillote, Teaching Manual for Sustainable Design Education: a preliminary look at the intended content with excerpts for immediate application in the classroom. IDEC Sustaining Design Taskforce. Julie Stewart-Pollack and Lauren E. Pillote, 2006.

[30] L. IGRIć, Social context, special needs / disability / deelopmental disorders and educational inclusion. Hrvatska Revija Za Rehabilitacijska Istrazivanja, 40(2), 151-164. 2004. Retrieved October 15, 2007, from Scopus database.

[31] F. B. Licht, Moradias Populares Acessíveis: o bom exemplo do departamento municipal de habitação de Porto Alegre. IAB-RS Instituto de Arquitetos do Brasil, outubro. Porto Alegre. 2007.

[32] C. Fielding, Implementation of research-based UK regulations for public transport vehicles with particular reference to contrast in bus and rail vehicles, 2005, Retrieved October 15, 2007, from Scopus database.

[33] WorldWatch Institute. Estado do Mundo 2004: estado do consumo e o consumo sustentável. Salvador: UMA.

[34] CORDE. Coordenadoria Nacional para a Integração da Pessoa Portadora de Deficiência. Accessed on 12/12/2006, Available at: http://www.mi.gov.br/sedh/ct/corde/dpdh/corde/ principal .asp/, 2004.

[35] MTE - Ministério doTrabalho e Emprego. Legislação: Normas Regulamentadoras. Accessed on: 10/05/2006, Available at: www.mte.gov.br/legislacao/normas_regulamentadoras/

[36]FADERS. Fundação de Atendimento ao Deficiente e ao Superdotado do Rio Grande do Sul. Accessed on: 8/01/2006, Available at:: http://www.faders.rs.gov.br/index.php 
[37] ABNT. Associação Brasileira de Normas Técnicas - ABNT. Accessed on: 29/05/2006, Available at: http://www.abnt.com.br/default.asp?resolucao=1024X768

[38] CAPES. CAPES: portal de periódicos. Accessed on: 10/11/2007, Available at: wwwperiodicoscapesgovbr

[39] F. Fogliatto, L.Guimarães, Design Macroergonômico: uma proposta metodológica para projetos de produto. Produto \& Produção. 3(3) 1-15, 1999.

[40] L.Guimarães, and F.Fogliatto, Macroergonomic Design: a new methodology for ergonomic product design. In: IEA'2000 (International Ergonomics Association Conference), San Diego (California). Proceedings of IEA'2000 (International Ergonomics Association Conference), 2000. v. 2. p. 328-328.

[41] H. Stone et al., Sensory Evaluation by Quantitative Descriptive Analysis. Food Technology, Chicago, US, v. 28, n.1, 1974.

[42] Universal Design New York University of North Carolina, The Center For Universal Design. Available at: $<$ http://www.design.ncsu.edu:8120/cud/univ_design/princ_overvie w.ht $0 \mathrm{~m}>$. Accessed on: 02/10/2003. 